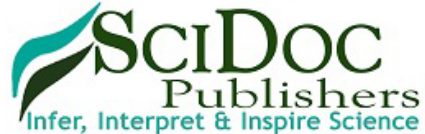

\section{The Effect of Two Acidic Time Exposure Followed by Remineralization Process on Roughness of Dental Enamel}

Research Article

Leqaa H. Qibi ${ }^{1 *}$, Fatima A. Mohammad ${ }^{2}$, Aisha A. Qasim³

${ }^{1}$ Department of Pedodontics, Orthodontics and Preventive Dentistry, University of Mosul, Mosul, Iraq.

${ }^{2}$ Al-Salam Hospital, Nineveh Health Directorate, Mosul, Iraq.

${ }^{3}$ Department of Pedodontics, Orthodontics and Preventive Dentistry, University of Mosul, Mosul, Iraq.

\title{
Abstract
}

Objective: The objective of the study was to assess the surface roughness of dental enamel and morphological effects produced in vitro by two acidic time exposure followed by remineralization process on enamel.

Materials and Methods: Samples of 120 sound human mandibular first premolars, extracted for orthodontic reasonfrom patients (18-25) years old were used in this study, the samples collected from Al-Noor dental center in Mosul city/ Iraq. The samples were randomly divided into six groups as follows: (A) artificial saliva exposing (control -ve), (B) Miranda exposing then managed by artificial saliva (control +ve) while the other four groups were demineralized by Miranda for 3 and 7 days, then the samples treated by four different dentifrices, all samples tested by rough-meter analysis and stereo-light microscope. Results: fluoridated dentifrices and artificial saliva exhibited a surface roughnesssignificantly at $\mathrm{P}<0.05$ than other samples. $\mathrm{SnF} 2$ dentifrice showed better and higher acid resistant than other types of dentifrice while Miranda inhibited the enamel surface roughness of teeth dental enamel.

Conclusions: The current study demonstrated the benefits of fluoridated dentifrices and artificial saliva in lowering the surface roughness of the previously demineralized enamel. On the other hand, increase exposure time to Miranda as soft acidic drink led to more erosion of the enamelsurface of the teeth.

Keywords: Dental Enamel; Remineralization; Surface Roughness; Miranda.

\section{Introduction}

Dental enamel is one of the most significant elements of the tooth, both functionally and aesthetically [1]. Thus, dental enamel is one of the strongestcomponents in the human body. It acts as a shelter to endure masticating forces,along withpreserving the underlying dentin and nerves from chemical and mechanical effects [2]. Therefore, itcan endure the most damage because of tooth wear. Furthermore, enamel does not redesigned or regrow when harmed, unlike other human tissues [3].

Dental demineralization is a process involvingthe destruction of hard substance of the tooth as a resultof prolonged and frequent exposure to acidic agents [4]. Supposing that the solubility of hydroxyapatite is low ( $\mathrm{pH}$ of 5.5), it turns to increase when the oral $\mathrm{pH}$ decreases [5].
Dental dmineralizationcan also be defined as the dissolution of dental hard tissues caused by acids of a non-bacterial origin. Dietary acids are considered as the most controllableandpredominant factor [6]. Because of the fact that, several chemical factors, like $\mathrm{pH}$, degree of saturation,type of acid, titratable acidityand chelating characters, have been identified to makethe erosivepotential of acids [7]. However, the acids important for tooth demineralization, come from intrinsic (for example, gastric refluxor eating disorders) or extrinsic sources. One significant extrinsic factor causing demineralization of the tooth is anexcessive expenditure of acidic foods and carbonated drinks, concurrently with changing lifestyles in the modern world the frequency of consumption of carbonated drinks and acidic foods is increased [8].

A lot of the most commonly used beverages have an adequately low $\mathrm{pH}$ to make demineralization of the enamel surface [9]. The acids presented in different drinks aid in improving the palatabil-

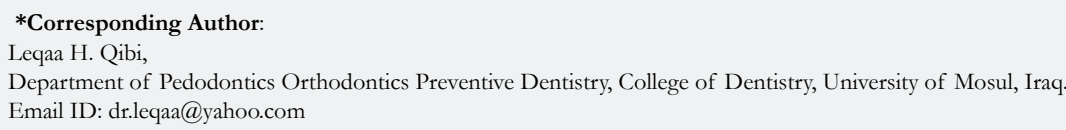

Copyright: Leqaa H. Qibi ${ }^{\circ} 2021$. This is an open-access article distributed under the terms of the Creative Commons Attribution License, which permits unrestricted use, distribution and reproduction in any medium, provided the original author and source are credited. 
ity of the drink, but simultaneously contributes to demineralize tooth structure. These acids include phosphoric acid, citric acid and malic acid [10]. In that way, the duration and frequencyof acid contact might determine the development and progression of erosivelesions [11].

In contrast, the use of fluoride-based products has regularly been the main component for the remineralization of hard tissues, due to its capability to incorporate into the enamel andchanging the hydroxyapatite to fluorapatite [12]. Fluoride in the systemicandtopical forms can react with hydroxyapatite and procedure fluorapatite or fluoridated hydroxyapatite [13]. Fluoride dentifrices persist the most broadly used method of delivering topical fluoride. Toothpastes may consist ofcalcium and fluoride ions separately or together in different compounds (remineralization systems) and therefore may decrease demineralization and enhance remineralization [14].

It may be trouble some to analyze erosion clinically it is early stages. At a macroscopic level the erosion may occur as smooth, silky glazed enamel [15]. Surface roughness is vertical deviation of a real surface from its ideal form. Surface roughness were evaluated via a profilometer. Surface profilometry was used to evaluate this surface roughness which estimates the dental tissue damage in relation to a non-managed area [16].

Therefore, the goal of this study was to estimate the effect of two acidic time exposure followed by remineralization process on enamel surface roughness.

\section{Materials and Methods}

\section{Sample preparation}

For handling this in vitro study, one hundred twenty (120) sound human mandibular first premolars were collected from Al-Noor dental center in Mosul city from patients between (18-25) years old extracted for orthodontic reason, samples had been collected within one year from April/2019 to April/2020. After extraction, patients were learned that their teeth would be used in this study and verbal approval was gathered.

The inclusion criteria, which included: complete root development, no carious lesions and no cracks, no restorations, no fractures in the labial surfaces of the enamel.

The exclusion criteria, which included: pregnant women, smoker patients.

After washing the extracted teeth under running water for one minute with brushing by fine toothbrush [18], these teeth were reserved in a distilled water until the time of the first roughness recording [19].

After removingthe root from the crown at cement-enamel junction by using a diamond disc bur in the high speed pencil grinder cooled with water, the crown embedded in cylinders with acrylic resin (Major, Italy) with the buccal side of enamel exposed as displayed in figure (1).

These specimens were polished by using Ultrasonic polishing machine (Germany) with 600-grit sand paper (Buehler Ltd) that used to expose flat enamel and to make standardization to specimens [20].

\section{Sample grouping}

Samples were randomly divided into six groups (20 teeth in each group), all the samples were demineralized by immersed it in a Miranda solution which is a local soft drink available in Iraqi markets, as (demineralization solution: Carbonated water, high fructose corn syrup and/or sugar, citric acid, and ascorbic acid) for 10 minutes at $(25 \pm 1) \mathrm{C}^{\circ}$, this cycle repeated twice daily for 3 days and 7 days cycle, as follows:

Control -ve group: the sample immersed in a Miranda solution cycles only.

Control +ve group: the sample immersed in a Miranda solution cycles then treated with remineralization solution for 5 hours and stored at $(25 \pm 1) \mathrm{C}^{\mathrm{o}}$.

Remineralization solution prepared according to the formulation of [21] consist of $\mathrm{KCl}, \mathrm{MgCl}_{2}, \mathrm{CaCl}_{2}, \mathrm{~K}_{2} \mathrm{HPO}_{4}, \mathrm{KH}_{2} \mathrm{PO}_{4}$, deionized water and sodium carboxy methyl cellulose.

The remaining four groups of samples, exposed to a Miranda solution cycles then treated with a thin layer of four different dentifrices [G1 (0,321\%w/w) amine fluoride, G2 (0,321\% w/w) Sodium fluoride $(\mathrm{NaF}), \mathrm{G} 3(0.321 \% \mathrm{w} / \mathrm{w})$ Sodium monofluorophosphate $\left(\mathrm{Na}_{2} \mathrm{PO}_{3} \mathrm{~F}\right)$, and $\mathrm{G} 4(0.321 \% \mathrm{w} / \mathrm{w})$ Stannous fluoride $\left.\left(\mathrm{SnF}_{2}\right)\right]$ for three minutes repeatedthree times daily for 3 and 7 days.

\section{Sample Assessment}

Surface Topography Assessment: Stereo-light microscope magnification 200X- (Motic, China) as displayed in figure (1) is a helpful tool to examine the surface topography of enamel surface before and after exposing to Miranda solution, remineralization solution and four different dentifrices by applying a camera (Moticam 2000, Italy) connected to the microscope. The pictures

Figure 1. Teeth Samples and Stereo-light microscope.
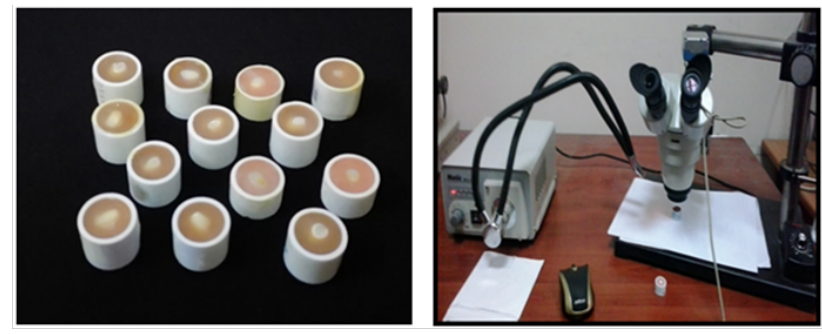
were then studied by a computer.

Roughness Assessment (Surface roughness test): For each sample, the mean enamel roughness $(\mathrm{Ra}, \mu \mathrm{m})$ were estimated before and after each treatment period with a surface rough-meter (Tokyo, Japan).

The buccal surface of the tooth was perpendicular to the surface rough-meter tip at a speed of 1 millimeter / second, with cutoffs $0.8 \mathrm{~mm}$ [19], three different measurements were recorded for each sample with a 0.25 cutoff. For each sample, The Ra value was the arithmetic mean of three estimations [22].

\section{Results}

Remineralization solution and Fluoridated dentifrices displayed a significant decrease in enamel surface roughness than other groups. Also G4 dentifrice showed a better effect than other types of dentifrices in decreasing surface roughness, while Miranda solution displayed demineralization of enamel and increased the enamel surface roughness. Micrographs of Stereo-light microscope for teeth enamel surface samples shown in figure (2).

\section{Roughness Assessment Result}

Comparison between teeth sample groups immersed in the Miranda solution (demineralization) for a three day cycle

The results of ANOVA Test that compare surface roughness test exhibited that there was a significant difference at $\mathrm{p} \leq 0.05$ of all groups in table (1).

Figure (3) displayed that (G4) dentifrice group has the apparent lowest mean result of surface roughness in correlation to other groups, while the Control negative group has highest mean result of the surface roughness in correlation to remaining groups.

Comparison between teeth sample groups immersed in the Miranda solution (demineralization) for seven day cycle

The results of ANOVA Test that compare surface roughness test displayed that there was a significantdifference at $\mathrm{p} \leq 0.05$ of all groups in table (2).

Figure (4) displayed that (G4) dentifrice group has an apparent lowest surface roughness mean result in correlation to other groups, while the Control Negative group has the highest mean result of surface roughness in correlation to other groups.

\section{Discussion}

Demineralization is a common marvel in the general population of developed countries.Peoples who consume acidic foods and drinks have a higher risk for some specific comestibles [23]. Tooth erosion is a continuous,permanent process resulting in destructiontooth enamel and even the dentin. Increased drinking carbonated beverages still a mainreason for dental demineralization. Estimation of surface roughness is one of the indicators to evaluate the dental erosion [9].

\section{For Miranda (demineralization) solution}

The result of current study demonstrated that there is increasing in the enamel surface roughness of the samples which immersed in Miranda (acidic, demineralization) solution, this result in agreement with Muñoz et al., (2004) study [24]. On the other hand, samples treated with remineralization solution and fluoridated dentifrice appeared regular and quite smooth surface which agree with other previous studies $[25,26]$.

Figure 2. Micrographs of Stereo-light microscope for teeth enamel surface samples after immersion in demineralization solution (three day and seven day) of demineralization, and after remineralization and using dentifrices (G1, G2, G3, and G4).

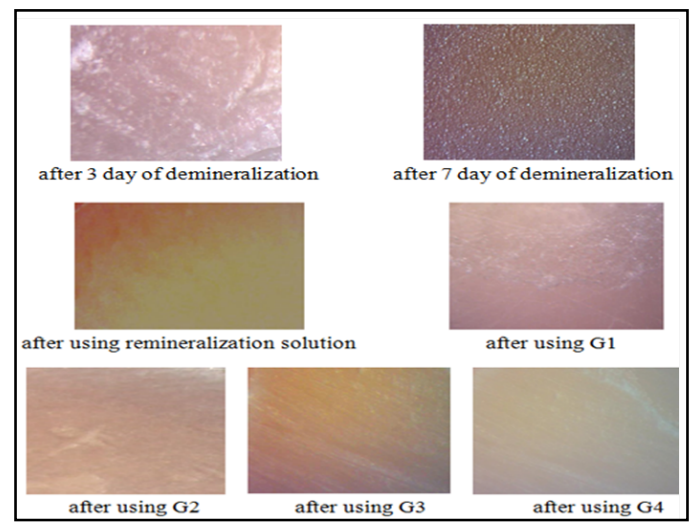

Table 1. ANOVA test results of surface roughness test between groups with demineralization by Miranda solution for three day cycle.

\begin{tabular}{|c|c|c|c|c|c|}
\hline Variance & $\begin{array}{c}\text { Sum of } \\
\text { squares }\end{array}$ & $\begin{array}{c}\text { Degree of } \\
\text { freedom }\end{array}$ & $\begin{array}{c}\text { Mean } \\
\text { square }\end{array}$ & F-value & P-value \\
\hline Between Groups & 52.72 & 5 & 10.544 & 511.061 & $0.000^{*}$ \\
\hline Within Groups & 2.352 & 114 & 0.021 & & \\
\hline Total & 55.072 & 119 & & & \\
\hline
\end{tabular}

* Significant difference existed at $\mathrm{p} \leq 0.05$ 
Figure 3. Mean, ANOVA and Standard Deviation for surface roughness result between sample groups immersed in a demineralization solution for a three day cycle.

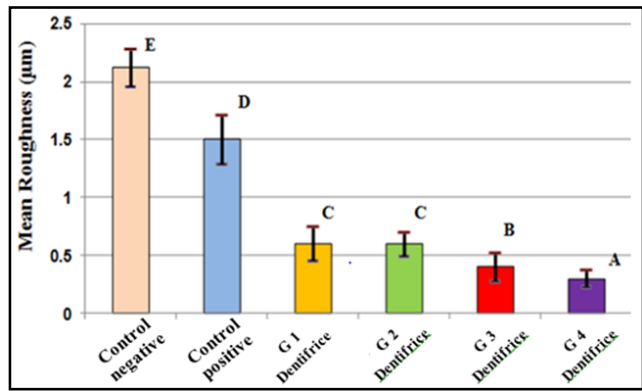

Figure 4. Mean, ANOVA and Standard Deviation for surface roughness result between sample groups exposed to Miranda solution for seven day cycle.

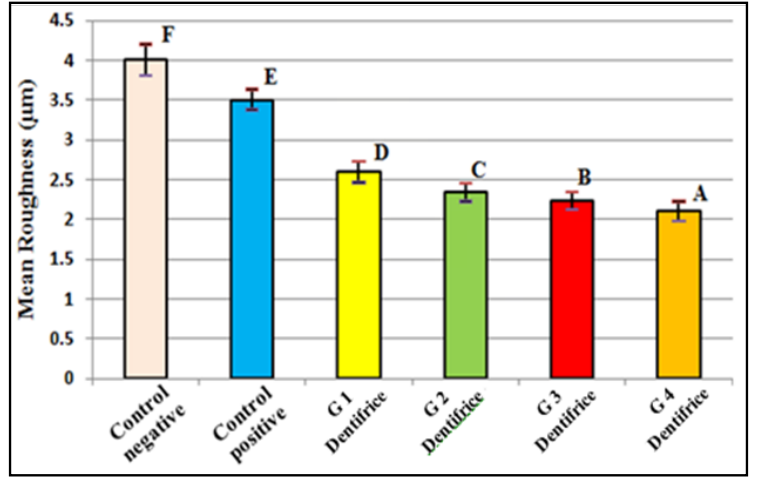

Table 2. ANOVA test results of surface roughness test between groups with demineralization by Miranda solution for seven day cycle.

\begin{tabular}{|c|c|c|c|c|c|}
\hline Variance & Sum of squares & Degree of freedom & Mean square & F-value & P-value \\
\hline Between Groups & 59.915 & 5 & 11.983 & 659.142 & $0.000^{*}$ \\
\hline Within Groups & 2.073 & 114 & 0.018 & & \\
\hline Total & 61.988 & 119 & & & \\
\hline
\end{tabular}

* Significant difference existed at $\mathrm{p} \leq 0.05$

Usually, the rates of remineralization and demineralization on the surface of the tooth are balanced to keep the teeth healthy. On the other hand, when teeth are exposed to an acidic medium for a long period of time, it simplyyields an unbalance between the processes of demineralization and remineralization [27].

Human tooth enamel is a highly mineralized structure. It commonly has a prismatic structure (rods and interrods) yet the outermost layer is a prismatic and is to a certain extent resistant to tooth surface erosion. This mineralized tissue is tightly packed with hydroxyapatite crystals, the other components are organic material and water. The erosive demineralization of enamel is a centripetal process which begins with a partial loss of surface mineral/hydroxyapatite crystals. This leads to increased surface roughness [6].

Also, the current study concluded that demineralization managed surface looked irregular, rough and porous, this may be due to the demineralization solution plays as an eroding acid that causes irregularity and porosity to enamel of dentine and loss of material from it $[28,29]$ this due to the fact that during an acidic attack, or a typical demineralization regime, chemical dissolution of both the organic and inorganic matrix components occur. This is brought about by the water content of enamel and dentin, which facilitate acid diffusion in and mineral content out of tooth [30].

According to resultsof present study there is increasing in surface roughness by increasing the exposuretime to demineralized (Miranda) solution, this result go with Adhani et al., (2015) study [31] who concluded that there is a relation between days of exposure, $\mathrm{pH}$ and demineralization of teeth that can cause dental demineralization, this may be due to the fact that the prolongation of exposure period can decrease the mineral concentration, this mean the short exposures to demineralizing solutions leading to low roughness because of the low enamel damage [32].

But these results were in disagreement withDawes, (2008) [33] who exhibitedthat the predicted demineralizing potential is relatively high for short exposures and low for long exposures, this implies that there's no direct relationship between exposure time and demineralization.

\section{For dentifrices and remineralization solution}

In the existing study dentifrice caused remineralization, this results in agreement with the result of Kato et al., (2010) [34] who showed that dentifrice is an ideal mode for protection tooth's surface from demineralization. Also agreed with the result of Lussi 
et al., (2008) [35] who concluded that the different fluoride concentrations and formulations had an effect in reduction of demineralization of dental enamel.

De- and remineralization appear depending on the degree of saturation of the interstitial fluids regarding the tooth mineral. This equilibrium is positively affected when calcium, fluoride and phosphate ions are added favoring dental remineralization. Furthermore, when fluoride is found, it will be incorporated into the newly formed mineral which is then less soluble. Toothpastes may contain calcium and fluoride ions separately or together in different compounds (remineralization systems) and may thus decrease demineralization and enhance remineralization $[15,36]$.

When remineralization occurs naturally, it needs outside intervention to happen effectively - and this means introducing fluoride. Fluoride, the ionic form of the element fluorine [37]. It acts by holding on to calcium and phosphate in the mouth, increasing enamel remineralization. Also, it prevents more decay by exchanging the normal enamel crystalline composition hydroxyapatite with stronger fluorapatite $\left(\mathrm{Ca}_{5}\left(\mathrm{PO}_{4}\right)_{3} \mathrm{~F}\right.$ or FA). FA starts demineralizing process at $4.5 \mathrm{pH}$, significantly lower $\mathrm{pH}$ than hydroxyapatite, giving the teeth a stronger protection from decay [38].

This study showed that $\mathrm{G} 4\left(\mathrm{SnF}_{2}\right)$ dentifrice group has a significant lowest surface roughness average value in correlation to other groups, This result in agreement with other previous studies $[39,40]$ whose concluded that $\mathrm{SnF}_{2}$ interacts with the tooth surface to prevent exposure of calcium on the enamel surface to increase its resistance to demineralisation therefore, $\mathrm{SnF}_{2}$ dentifrice is used widely in oral care products to help prevent/treat these conditions [41].

These results also in assention withHuysmans et al., (2011)[42] who founded that stannous fluoride dentifrice significantly reduced demineralizing effect.Also in assentionwith Eversole et al., (2014) [43] results who concluded that the marketed toothpaste defined with $\mathrm{SnF}_{2}$ may offerimproved protection of exposed surfaces of the tooth against dietary acid assault incomparison with the other products. Also, this result is in agreement with Khambe et al., (2014) [44] who concluded that $\mathrm{SnF}_{2}$ toothpaste represents aninterestingmechanistic approach for giving protection against dietary, erosive acid challenges.

The potential of conventional fluorides, such as SnF2, to inhibit erosive demineralization is chiefly related to the production of a calcium fluoride $\left(\mathrm{CaF}_{2}\right)$-layer. This layer is supposed to act as a physical barrier obstructing the contact of the acid with the underlying enamel surface or to behave as a mineral reservoir, which is attacked by the erosive challenge. Subsequently, calcium and fluoride released might rise the saturation level with respect to dental hard tissue, sostimulating remineralization [45].

On the other hand, these results are in argument with previous study 35, which founded thatthe influence of stannous fluoride $\left(\mathrm{SnF}_{2}\right)$ dentifrice on demineralization failed to find an important effect, or difference with sodium fluoride $(\mathrm{NaF})$ toothpaste.

Another study showed that, $\mathrm{SnF}_{2}$ toothpastes were shown to be superior in decreasing dental erosion in comparison with $\mathrm{NaF}$ dentifrices, but not combined demineralization andabrasion [46]. It has been discussed that the quantity of fluoride found in the toothpaste slurry is not directly related to the possible protective effect of toothpastes against enamel surface demineralization [46]. It is supposed that the way of action of fluoride against demineralization happened by prompting the making of a layer on the demineralized enamel surface, which is consisted of $\mathrm{CaF}_{2}$ (in the case of conventional compounds, such as $\mathrm{NaF}$ ) or of metal-rich surface precipitates (in the case of $\mathrm{SnF}_{2}$ ). These layers should act as a physical barrier whichprotect the tooth structure from the effect of acid, so buffering the acids or stimulating precipitation of mineral [47]. However, fluoridation by toothpastes is less effective in inhibiting erosion of enamel and dentin [48].

\section{Conclusion}

The present study demonstrates the following:

- The benefits of fluoridated dentifrices and the remineralization solution in decreasing surface roughness of the demineralized enamel surface.

- Also Stannous fluoride $\left(\mathrm{SnF}_{2}\right)$ dentifrice showed better and higher remineralization effect after demineralization in comparison to other groups.

- The present study displays that many of the most widely used beverages like Miranda have anadequately low $\mathrm{pH}$ to makedemineralization of the enamel surface. Miranda solution as acidic solution had the greatest demineralizing effects and the prolonging time of exposure to Miranda solution leading to more demineralization to dental enamel surface.

Lastly, fordentists, it is important to prevent drinking of Miranda and other demineralizing solution or at least reducing the consumption of soft drinks. Interest in using a fluoridatedtoothpaste especially for children as defensive mechanisms doespresent in the oral cavity to neutralize the acids found in these drinks, repeated use of these drinks leads to permanent destruction to the tooth surface.

\section{Limitations of the Study}

Firstly, the existing study was run under in vitro conditions, which cannot reproduce the complexity of the oral cavity, thereforeuse artificial saliva instead of normal saliva. However, human saliva may undergo changes in its compositionwhen it is out of the oral environment, leading to reduced protective capacity. Additionally, the apply of saliva as research material may bear certain difficultiesbecause of its inherent variability and instability. On the other hand, there are a limitation and complications of using natural saliva, for example,consuming time to collect andquickly decomposing.

Secondly, it measures erosion based on enamel surface roughness and not on the amount of mineral lost.Furthermore, this study was conducted in vitro and did not consider the oral soft tissues which serve as reservoirs for fluoride ions.

\section{References}

[1]. Akasapu A, Hegde U, Murthy PS. Enamel Surface Morphology: An Ultrastructural Comparative Study of Anterior and Posterior Permanent Teeth. J Microsc Ultrastruct. 2018 Jul-Sep;6(3):160-164. Pubmed PMID: 30221142.

[2]. Lu C, Nakamura T, Korach CS. Effective property of tooth enamel: mono- 
clinic behavior. J Biomech. 2012 May 11;45(8):1437-43. Pubmed PMID: 22405497.

[3]. Wu YQ, Arsecularatne JA, Hoffman M. Attrition-corrosion of human dental enamel: A review. Biosurface and Biotribology. 2017 Dec 1;3(4):196-210.

[4]. Memarpour M, Shafiei F, Rafiee A, Soltani M, Dashti MH. Effect of hydroxyapatite nanoparticles on enamel remineralization and estimation of fissure sealant bond strength to remineralized tooth surfaces: an in vitro study. BMC Oral Health. 2019 May 28;19(1):92. Pubmed PMID: 31138191.

[5]. Jensdottir T, Bardow A, Holbrook P. Properties and modification of soft drinks in relation to their erosive potential in vitro. J Dent. 2005 Aug;33(7):569-75. Pubmed PMID: 16005796.

[6]. Chan AS, Tran TTK, Hsu YH, Liu SYS, Kroon J. A systematic review of dietary acids and habits on dental erosion in adolescents. Int J Paediatr Dent. 2020 Nov;30(6):713-733. Pubmed PMID: 32246790.

[7]. Lussi A, Megert B, Shellis RP, Wang X. Analysis of the erosive effect of different dietary substances and medications. Br J Nutr. 2012 Jan;107(2):252-62. Pubmed PMID: 21733310.

[8]. Lussi A, Schlueter N, Rakhmatullina E, Ganss C. Dental erosion--an overview with emphasis on chemical and histopathological aspects. Caries Res. 2011;45 Suppl 1:2-12. Pubmed PMID: 21625128.

[9]. Rajeev G, Lewis AJ, N S. A time based objective evaluation of the erosive effects of various beverages on enamel and cementum of deciduous and permanent teeth. J Clin Exp Dent. 2020 Jan 1;12(1):e1-e8. Pubmed PMID: 31976037.

[10]. Torres CP, Chinelatti MA, Gomes-Silva JM, Rizóli FA, Oliveira MA, Palma-Dibb RG, et al. Surface and subsurface erosion of primary enamel by acid beverages over time. Braz Dent J. 2010;21(4):337-45. Pubmed PMID: 20976385.

[11]. Kregiel D. Health safety of soft drinks: contents, containers, and microorganisms. Biomed Res Int. 2015;2015:128697. Pubmed PMID: 25695045.

[12]. Attin T, Becker K, Wiegand A, Tauböck TT, Wegehaupt FJ. Impact of laminar flow velocity of different acids on enamel calcium loss. Clin Oral Investig. 2013 Mar;17(2):595-600. Pubmed PMID: 22526895.

[13]. Kensche A, Pötschke S, Hannig C, Richter G, Hoth-Hannig W, Hannig M. Influence of Calcium Phosphate and Apatite Containing Products on Enamel Erosion. ScientificWorldJournal. 2016;2016:7959273. Pubmed PMID: 27430013.

[14]. Ozsvath DL. Fluoride and environmental health: a review. Reviews in Environmental Science and Bio/Technology. 2009 Mar;8(1):59-79.

[15]. Amaechi BT, van Loveren C. Fluorides and non-fluoride remineralization systems. Monogr Oral Sci. 2013;23:15-26. Pubmed PMID: 23817057.

[16]. ten Cate JM, Imfeld T. Dental erosion, summary. Eur J Oral Sci. 1996 Apr;104(2 ( Pt 2)):241-4. Pubmed PMID: 8804892.

[17]. Schlueter N, Hara A, Shellis RP, Ganss C. Methods for the measurement and characterization of erosion in enamel and dentine. Caries Res. 2011;45 Suppl 1:13-23. Pubmed PMID: 21625129.

[18]. Karacaoglu F, Tuzcel NY, Akkaya M. A comperative evaluation of 3 different polishing methods on tooth surface roughness. J Biomedical Sci. 2016;6:1.

[19]. Degrazia FW, Genari B, Ferrazzo VA, Santos-Pinto AD, Grehs RA. Enamel Roughness Changes after Removal of Orthodontic Adhesive. Dent J (Basel). 2018 Aug 6;6(3):39. Pubmed PMID: 30082662.

[20]. International Organization for Standardization. Dental Materials-Testing of Adhesion to Tooth Structure. International Organisation for Standardization; 2003.

[21]. Amaechi BT, Higham SM, Edgar WM. Factors influencing the development of dental erosion in vitro: enamel type, temperature and exposure time. J Oral Rehabil. 1999 Aug;26(8):624-30. Pubmed PMID: 10447814.

[22]. Melo CF, Manfroi FB, Spohr AM. Microhardness and roughness of enamel bleached with $10 \%$ carbamide peroxide and brushed with different toothpastes: an in situ study. J Int Oral Health. 2014 Jul;6(4):18-24. Pubmed PMID: 25214727

[23]. Schlueter N, Luka B. Erosive tooth wear - a review on global prevalence and on its prevalence in risk groups. Br Dent J. 2018 Mar 9;224(5):364-370. Pubmed PMID: 29495027

[24]. Muñoz CA, Stephens JA, Proskin HM, Ghassemi A. Clinical efficacy evaluation of calcium, phosphate, and sodium bicarbonate on surface-enamel smoothness and gloss. Compend Contin Educ Dent. 2004 Sep;25(9 Suppl 1):32-9. Pubmed PMID: 15645905.

[25]. Do Couto CF, de Mello MDS, Carvalho W. Degradation of acidic solutions and bacterial adherance on the surface of indirect polymeric matrix. Int J Sci Dent.2013; 1(39): 47-54

[26]. Yamamoto ETC, Vanderlei A, Amara R.Influence of three types of drinks on the surface of human dental enamel: in vitro study. RGO. Revista Gaúcha de
Odontologia (Online). 2013 Mar;61(1):41-6.

[27]. Abou Neel EA, Aljabo A, Strange A, Ibrahim S, Coathup M, Young AM, et al. Demineralization-remineralization dynamics in teeth and bone. Int J Nanomedicine. 2016 Sep 19;11:4743-4763. Pubmed PMID: 27695330.

[28]. Moura SK, Pelizzaro A, Dal Bianco K, de Goes MF, Loguercio AD, Reis A, et al. Does the acidity of self-etching primers affect bond strength and surface morphology of enamel? J Adhes Dent. 2006 Apr;8(2):75-83. Pubmed PMID: 16708718

[29]. Wilder-Smith CH. Quantification of dental erosions in patients with GERD using optical coherence tomography before and after double-blind, randomized treatment with esomeprazole or placebo. The American journal of gastroenterology. 2009 Nov;104(11):2788.

[30]. Shellis RP, Featherstone JD, Lussi A. Understanding the chemistry of dental erosion. Monogr Oral Sci. 2014;25:163-79. Pubmed PMID: 24993265.

[31]. Adhani R., Sukmana BI, Suhartono E. Effect pH on Demineralization Dental Erosion. Int J Chem Eng Appl.2015; 6: 2.

[32]. Ganss C, Lussi A, Klimek J. Comparison of calcium/phosphorus analysis, longitudinal microradiography and profilometry for the quantitative assessment of erosive demineralisation. Caries Res. 2005 May-Jun;39(3):178-84. PubmedPMID: 15914978 .

[33]. Dawes C. Salivary flow patterns and the health of hard and soft oral tissues. J Am Dent Assoc. 2008 May;139 Suppl:18S-24S. Pubmed PMID: 18460676.

[34]. Kato MT, Lancia M, Sales-Peres SH, Buzalaf MA. Preventive effect of commercial desensitizing toothpastes on bovine enamel erosion in vitro. Caries Res. 2010;44(2):85-9. Pubmed PMID: 20145397.

[35]. Lussi A, Megert B, Eggenberger D, Jaeggi T. Impact of different toothpastes on the prevention of erosion. Caries Res. 2008;42(1):62-7. Pubmed PMID: 18087151.

[36]. Barbour ME, Finke M, Parker DM, Hughes JA, Allen GC, Addy M. The relationship between enamel softening and erosion caused by soft drinks at a range of temperatures. J Dent. 2006 Mar;34(3):207-13. Pubmed PMID: 16112333.

[37]. Usha C, Sathyanarayanan R. Dental caries-A complete changeover (Part I). Journal of conservative dentistry: JCD. 2009 Apr;12(2):46.

[38]. CFR - Code of Federal Regulations Title 21.” Accessdata.fda.gov, 1 Apr. 2018, https://www. accessdata. fda. gov/scripts/cdrh/cfdocs/cfcfr/CFR Search.cfm?C-FRPart=21.

[39]. Fernández CE, Fontana M, Samarian D, Cury JA, Rickard AH, GonzálezCabezas C. Effect of Fluoride-Containing Toothpastes on Enamel Demineralization and Streptococcus mutans Biofilm Architecture. Caries Res. 2016;50(2):151-8. Pubmed PMID: 27073873.

[40]. Cheng X, Liu J, Li J, Zhou X, Wang L, Liu J, et al. Comparative effect of a stannous fluoride toothpaste and a sodium fluoride toothpaste on a multispecies biofilm. Arch Oral Biol. 2017 Feb;74:5-11. Pubmed PMID: 27838508.

[41]. Fernando JR, Shen P, Sim CPC, Chen YY, Walker GD, Yuan Y, Reynolds C, Stanton DP, MacRae CM, Reynolds EC. Self-assembly of dental surface nanofilaments and remineralisation by SnF2 and CPP-ACP nanocomplexes. Sci Rep. 2019 Feb 4;9(1):1285. Pubmed PMID: 30718577.

[42]. Huysmans MC, Jager DH, Ruben JL, Unk DE, Klijn CP, Vieira AM. Reduction of erosive wear in situ by stannous fluoride-containing toothpaste. Caries Res. 2011;45(6):518-23. Pubmed PMID: 21985895.

[43]. Eversole SL, Saunders-Burkhardt K, Faller RV. Erosion protection comparison of stabilised SnF2, mixed fluoride active and SMFP/arginine-containing dentifrices. Int Dent J. 2014 Mar;64 Suppl 1:22-8. Pubmed PMID: 24571701.

[44]. Khambe D, Eversole SL, Mills T, Faller RV. Protective effects of SnF2 - Part II. Deposition and retention on pellicle-coated enamel. Int Dent J. 2014 Mar;64 Suppl 1:11-5. Pubmed PMID: 24571699.

[45]. Ganss C, Schlueter N, Klimek J. Retention of KOH-soluble fluoride on enamel and dentine under erosive conditions--A comparison of in vitro and in situ results. Arch Oral Biol. 2007 Jan;52(1):9-14. Pubmed PMID: 17049481.

[46]. Ganss C, Lussi A, Grunau O, Klimek J, Schlueter N. Conventional and antierosion fluoride toothpastes: effect on enamel erosion and erosion-abrasion. Caries Res. 2011;45(6):581-9. Pubmed PMID: 22156703

[47]. Magalhães AC, Wiegand A, Rios D, Buzalaf MA, Lussi A. Fluoride in dental erosion. Fluoride and the oral environment. 2011;22:158-70.

[48]. Ganss C, Klimek J, Brune V, Schürmann A. Effects of two fluoridation measures on erosion progression in human enamel and dentine in situ. Caries Res. 2004 Nov-Dec;38(6):561-6. Pubmed PMID: 15528912. 